\title{
Theoretical Reason: Why Do Lysine And Several Vitamins Have Enzymatic Activity? And Further Suggestions
}

\author{
Hyeonhi R. Park¹, Kunjoo DA. Kim², Jiah A. Kim³, Rosa Kim, Alain Hamon5, Sohwa T. Kim6, Yongkook Kim, \\ Sangdeog A. Kim8*
}

${ }^{1}$ Department of Elderly care and welfare, Joongbu University, Kumsan, Republic of Korea ROK,

2Department of History, Yonsei University, Seoul, ROK

3Départment d'Expertise economique, Université de Paris-Est Creteil, Paris, France

${ }^{4}$ Spécialité d'Economie politique, Ecole des Hautes Etudes en Sciences Sociales, Paris, France

5 L'Ecole Internationale Jean-Mermoz, Abidjan, Cote d'Ivoire

${ }^{6}$ Department of French language and literature, Seoul Women's University, Seoul, ROK

7Department of Dairy Science, Chungnam National University, Daejeon, ROK,

${ }^{8}$ Department of Companion animal and animal resources science, Joongbu University, Kumsan, ROK

\section{*Corresponding Author}

Sangdeog A. Kim

\section{Article History}

Received: 02.12.2019

Accepted: 09.12.2019

Published: 14.12 .2019

\begin{abstract}
With this lysine-derived part, lysine has a favourable (or essential) effect maintaining stable condition without breaking even after $\mathrm{NH} 2$ deletion in the animal or human body. As further suggestions: Several water soluble vitamin B groups; flavine-adenine dinucleotide, pantothenic acid, and cobamamide (B12) have similar two groups in their own chemical structure and they act as coenzyme [1]. It is thought that this (two similar groups) in the chemical structure gives the material to work as a special effect in the body as a coenzyme. The activating effect of several water soluble B-group vitamins might be resulted from the emission of energy with the turmoil on pending in the centre of the molecule. In another expression, the rotation or vibration or seesawing of the two parts among the molecule. Here, the pairs of the molecule had to be not the same structure but to be the structure of similarity. Through our theoretical research it is considered that the structure of lysine-derived material $\left(\mathrm{C}^{2} \mathrm{H} 12 \mathrm{~N} 2 \mathrm{O} 3\right)$ is similar to the structure of several water soluble B-group vitamins (cobamamide (B12), flavine-adenine dinucleotide, pantothenic acid).
\end{abstract}

Keywords: Iysine, seesawing of the two parts, some enzymatic activities, theoretical research, water soluble vitamins.

\section{INTRODUCTION}

This is, of course, brings us into the realm of catalysis, and the story of biochemistry is in large measure the story of the protein molecules, called enzymes, that catalyze cellular reactions [2]. The aim of this article to know the possibility of theoretical suggestion for the chemical material. This method is to see its chemical form of a material and to anticipate the function of a material. The figure of acetyl-coenzyme is $\mathrm{CH} 3 \mathrm{COOH}$.

$3 \mathrm{HC}----\mathrm{COOH}$

The $\mathrm{CH} 3$ group and $\mathrm{COOH}$ group have similar structure, but they are not same. We think that if a material with two similar chemical structures while they have some difference, the material can have a property of enzymatic activity. Another instance for this structure is the oleic acid, an unsaturated fatty acid.

HOOC-CCCCCCCC $=====\operatorname{CcCcccccC}$

A last drop of liquid from a pipette is around 0.2 milliliter (ml), but the number of lysine (its molecular weight is 146) in the liquid volume is more than $1.3 \times 10^{19}$. This fact means that the size of lysine molecular is extremely small. It is thought that there is some $\mathrm{CO}$ instead of $\mathrm{CH} 2$ in the lysine molecule in the body solution.

Copyright @ 2019: This is an open-access article distributed under the terms of the Creative Commons Attribution license which permits unrestricted use, distribution, and reproduction in any medium for non commercial use (NonCommercial, or CC-BY-NC) provided the original author and source are credited. 


\section{RESULTS AND DISCUSSION}

When amino group ( $\mathrm{NH} 2$ ) deleted from the molecule of amino acid, carbon structure of other amino acids will be broken easily, but the structure of lysine will not be easily broken [3]. What is the reason of the especially strong property of lysine? It is observed that the chemical structure of amino acids and the structure of lysine is different from other amino acids [1]. It is thought that there is a relation between the two pair of the similar 3-carbons and this strong structure of lysine and the essentiality of the amino acid in the body. At first, alanin has three carbons, as follows;

$\mathrm{NH} 2$

$\mathrm{CH} 3----\mathrm{CH}----\mathrm{COOH}$

(Alanin, C3)

Alanine has a property of producing glutamic acid [4]. The next description is our imagination; alanin will be changed into asparagin. Asparagin has four carbons, and it is not stable. This fact means that asparagin will be changed into another material.

$\mathrm{NH} 2 \quad \mathrm{NH} 2$

$\mathrm{CO}-\mathrm{CH} 2----\mathrm{CH}-\mathrm{COOH}$

(Asparagin, C4)

And the asparagine, advanced from alanine, will be again changed into glutamic acid and to glutamine. But the glutamine is until unstable, and it might be changed into other material.

$\mathrm{NH} 2 \quad \mathrm{NH} 2$
$\mathrm{CO}-\mathrm{CH} 2-----\mathrm{CH}$------CH-COOH
(Glutamine, $\mathrm{C5}$ )

The next things are not a result of the experiment but that of our imagination. Alanine ( 3 carbons) will be changed to asparagine (4 carbons). And it will be carried out from asparagine to glutamine ( 5 carbons). Finally glutamine will be changed to lysine-derived material (6 carbons).

The next is lysine, very simple. The number in the parenthesis was named in order to compare lysine with a lysine-derived material, which will be shown below;

$\mathrm{NH} 2(4)$

$\mathrm{CH} 2(3)-\mathrm{CH} 2(2)-\mathrm{CH} 2-----\mathrm{CH} 2-\mathrm{CH}-\mathrm{COOH}(1)$

(Lysine, C6H14N2O2)

The result is that, $\mathrm{CH} 2$ (3) on changing to $\mathrm{CO}(5)$ springs up and flee to the site of $\mathrm{CH} 2$ (2). That means the two function groups of $\mathrm{CO}(5)$ and $\mathrm{CH} 2$ (2) change their original sites shown as the next lines. We call the reaction as controlled thermodynamics [5].

$\mathrm{NH} 2(4)$

$\mathrm{NH} 2$

$\mathrm{CH} 2(2)-\mathrm{CO}(5)-\mathrm{CH} 2-----\mathrm{CH} 2-\mathrm{CH} \mathrm{COOH}(1)$

(Lysine-derived material, $\mathrm{C} 6 \mathrm{H} 12 \mathrm{~N} 2 \mathrm{O} 3)$

This type of lysine-derived material, $\mathrm{C} 6 \mathrm{H} 12 \mathrm{~N} 2 \mathrm{O} 3$, it is not known as a real existing material [6], but it is thought that it really exists because of potentially well variable and well modified molecule shape and great number of molecules even in an extremely small quantity in the body solution. Two separated parts are not same but mutually very similar in the lysine-derived material $(\mathrm{C} 6 \mathrm{H} 12 \mathrm{~N} 2 \mathrm{O} 3)$. There is a difference of $\mathrm{CO}(5)$ and $\mathrm{CH} 2$ (2) sites, both sites exchanged. We imagine that there are some parts of this molecule in the lysine solution in the body. With this lysine-derived part, lysine has a favourable (or essential) effect maintaining stable condition without breaking even after $\mathrm{NH} 2$ deletion in the animal or human body.

\section{FuRTHER Suggestions}

Several water soluble vitamin B groups; flavine-adenine dinucleotide, pantothenic acid, and cobamamide (B12) have similar two groups in their own chemical structure and they act as coenzyme [1]. It is thought that this (two similar groups) in the chemical structure gives the material to work as a special effect in the body as a coenzyme. The activating effect of several water soluble Bgroup vitamins might be resulted from the emission of energy with the turmoil on pending in the centre of the molecule. In another expression, the rotation or vibration or seesawing of the two parts among the molecule. Here, the pairs of the molecule had to be not the same structure but to be the structure of similarity. Through our theoretical research it is considered that the structure of lysinederived material $(\mathrm{C} 6 \mathrm{H} 12 \mathrm{~N} 2 \mathrm{O} 3)$ is similar to the structure of several water soluble B-group vitamins (cobamamide (B12), flavineadenine dinucleotide, pantothenic acid). And the function of lysine might be similar to that of several water soluble vitamins. Therefore, it is assumed that lysine has theoretically some enzymatic activity. 


\section{Conclusions}

Through our theoretical research it is considered that the structure of lysine-derived material $(\mathrm{C} 6 \mathrm{H} 12 \mathrm{~N} 2 \mathrm{O} 3)$ is similar to the structure of several water soluble B-group vitamins (cobamamide (B12), flavineadenine dinucleotide, pantothenic acid). And the function of lysine might be similar to that of several water soluble vitamins. Therefore, it is assumed that lysine and several vitamins have theoretically some enzymatic activities.

\section{ACKNOWLEDGEMENTS}

We thank Mr Yeonghag Park and Mrs Hilye Sarah Kim, Mr Ilsoo Joseph Kim and Mrs Bohwa Kim, Ms Jieun Agatha Kim. We thank Father Jean Blanc and Father Hifumi Iwazaki, Professor Tae Song Koh, Professor Jae-In Yun and Professor Ik Suk Yun, Professor Mitsuaki Ohshima and Professor Ryosei Kayama and Professor Shigekata Yoshida, Professor Byung Hoon Park, Professor Yungho Chung, Professor Inhag Choi and Professor Taeho Chung and the students of Department of Companion animal and animal resources science in Joongbu University. We thank Mrs Tamako Hayashi and Mr Yoshihiro Hayashi, Mrs Francine Tenaillon and Professor Nicolas Tenaillon. We thank Mrs SookJa Nam, Mrs Sookja Martha Min, Mrs Kisoon Cecile Song, Mrs Fasan of INA P-G in France, and the members of Daejeon Ludovich of Ordo Franciscanus Saecularis (OFS).

\section{REFERENCES}

1. Lee, S.R. Jeong, J. An, J.G., \& Mun, W. (1995). Saengmulhwahag (Biological chemistry), Korean National Open University Press , Seoul.

2. Kilgour, G. L. (1981). Fundamentals of Biochemistry, D. Van Nostrand Company. New York.

3. Ko, Y.D. (2008). 16 persons, Dongmulyongyanghag(Animal nutrition), Yuhan Publishing Co, Seoul.

4. Han, I.K. \& Jeong, C.Y. (1993). Gatchugyongyanghag (Nutrition of Livestock), Korean National Open University Press, Seoul.

5. Arnaud, P. (1998). Chimie physique (cours)(4e edition), Dunod, Paris. John R. Etherington, Environment and plant ecology (seco nd edition), John Wiley and Sons, Chichester.I

6. Windholz, M. (1983). The Merck Index (tenth edition), Merck, Rahway. 